\title{
Sensory and pain threshold characteristics to laser stimuli
}

\author{
LARS ARENDT-NIELSEN, PETER BJERRING \\ From the Department of Medical Informetics, Aalborg University, Aalborg, and the Department of \\ Dermatology, Marselisborg Hospital, Aarhus, Denmark
}

SUMMARY The clinical applications of thermal sensory and pain thresholds have been very limited due to large intra-individual variations. In the present paper $\mathrm{CO}_{2}$ and argon lasers were used as thermal stimulators, and the different factors (stimulus parameters and skin conditions) affecting the thresholds are described. The intra-individual variations obtained in sensory $(9 \cdot 3 \%)$ and pain (4.3\%) thresholds were very low, which suggests that the method can be applied for clinical purposes.

According to Wall $^{1}$ radiant heat is particularly favourable for investigation of thermal thresholds because (1) it can elicit a specific afferent activity without contamination from mechanosensitive receptors, (2) it can be applied to different skin areas. Lasers are especially suitable as thermal pain stimulators, since they can generate intense and brief heat pulses. ${ }^{23}$ The sensory response to graded $\mathrm{CO}_{2}$ laser stimulation ranges from a pre-pain sensation to strong stabbing pain with burning after sensation. ${ }^{45}$

The aim of the present study was to develop a method where a high reproducibility in thermal thresholds could be obtained. Sensory and pain thresholds were elicited by an infrared $\mathrm{CO}_{2}(10.6 \mu \mathrm{m})$ and a visible argon $(0.488$ and $0.515 \mu \mathrm{m})$ laser and the influence of stimulus parameters, skin characteristics and skin temperature was studied.

$\mathrm{CO}_{2}$ lasers have two disadvantages: (1) the beam cannot be transmitted by optical fibres, and (2) the superficial skin temperatures following a stimulus become very high because infrared $\mathrm{CO}_{2}$ radiation is fully absorbed within the very superficial skin layer. ${ }^{6}$ The high skin temperatures can result in superficial burn lesions. ${ }^{478} \mathrm{CO}_{2}$ radiation has the advantage that less than $2 \%$ of the applied energy is reflected from the skin surface independent of skin pigment. ${ }^{9}$

The disadvantage with argon laser stimulation is the high reflectance ( 30 to $40 \%$ ) from the skin

Address for reprint requests: Dr Lars Arendt-Nielsen, Department of Medical Informetics, Aalborg University, Strandvejen 19, DK-9000 Aalborg, Denmark.

Received 24 March 1987.

Accepted 8 June 1987 surface. ${ }^{10}$ The advantages are: (1) that argon laser light can be transmitted by quartz fibre, which make this laser type more appropriate for clinical purposes, (2) the visible argon light $(0.488$ to $0.515 \mu \mathrm{m})$ penetrates much deeper ${ }^{11} 12$ giving a more direct energy transfer into the deeper dermal layers, which reduce the superficial skin temperatures and activate the receptors more directly. This is because the energy is absorbed by the melanin in the basal epidermal layers, and by the haemoglobin in the papillary capillaries and in the superficial vascular plexus. The heat is then conducted directly to the nearby receptors.

The present study showed that argon lasers are suitable as thermal stimulators. Thermal thresholds are, however, modulated by stimulus parameters, skin temperature and thickness. These demand standard experimental conditions when thermal thresholds are used for quantitative comparisons.

\section{Methods}

Subjects All volunteers gave their written consent according to the Declaration of Helsinki. During the experiment the volunteers were resting comfortably and wore protective goggles.

Stimulation A surgical $\mathrm{CO}_{2}$ laser (Sharplan, 1040, Laser Industries, Israel) was used for infrared $(10.6 \mu \mathrm{m})$ stimulation. The output power could be adjusted from 0.01 $\mathrm{W}$ to $38 \mathrm{~W}$. Stimulus duration was adjustable in four steps, $50 \mathrm{~ms}, 100 \mathrm{~ms}, 200 \mathrm{~ms}$, and $500 \mathrm{~ms}$. The laser was operated in $\mathrm{TEM}_{00}$ mode. A $0.001 \mathrm{~W}$ HeNe laser visualised the stimulation site.

The output from an argon laser (Lexel Aurora 150, Cooper Medical, USA) was transmitted via quartz fibre to a handpiece with adjustable beam diameter $(0 \cdot 4-6 \mathrm{~mm})$. The 
laser was operated in TEM $_{00}$ mode. Output power could be adjusted from $0.005 \mathrm{~W}$ to $2.9 \mathrm{~W}$. The wave lengths were $0.488 \mu \mathrm{m}$ (blue) and $0.515 \mu \mathrm{m}$ (green). An external laser power meter (Ophir, Israel) was used to measure the dissipated output power. A continuous low energy beam $(0.005 \mathrm{~W})$ from the argon laser visualised the stimulation site.

Threshold determination To avoid any acoustical interference synchronised to the stimulus white noise was given through earphones. The stimulus was applied to the dorsum (C7-dermatome) of the left hand within a target area of $2 \times 3 \mathrm{~cm}^{2}$. Repeated stimulation at identical spots within the area was avoided to exclude the effect of receptor fatigue and receptor sensitisation. The intervals between stimuli were random with a mean of 30 seconds (range 15 to 45). The skin temperature on the dorsum of the hand was monitored, and kept constant $\left(33 \pm 2{ }^{\circ} \mathrm{C}\right)$ during the experiment.

Sensory and pain thresholds were defined as rating 1 and 3 respectively on a 7 point scale (table). The thresholds were calculated as a mean of five ascending and five descending series of stimulation.

Influence of skin temperature The influence of skin temperature on sensory and pain thresholds was estimated in 12 subjects (nine men, mean age 28 years, range $18-34$, and three women, mean age 30 years, range 23-36). At each test the sensory and pain thresholds were determined for the following skin temperatures: $28,30,32,34,36,38$ and $40^{\circ} \mathrm{C}$.

A local area $\left(4 \mathrm{~cm}^{2}\right)$ was heated by a Peltier device, to the decided temperature. The temperature measured was used as feedback to a control unit, in order to keep the temperature constant $\left( \pm 0 \cdot 1^{\circ} \mathrm{C}\right)$. The laser beam ( $200 \mathrm{~ms}$ duration, $3 \mathrm{~mm}$ spot diameter) could reach the skin through a small hole in the middle of the element. The element was moved after each stimulation. A subsequent heating was started when the skin temperature was returned to its initial value.

The influence of skin thickness Skinfold thickness was determined by a caliper in 45 points on the lateral part of the legs in one subject (male, 28 years). Skin thickness was calculated as $0.5 \times$ skinfold thickness. The argon laser stimulus had a duration of $200 \mathrm{~ms}$, and a diameter of $3 \mathrm{~mm}$. Skin preparation and reflection The skin reflection was measured in 12 subjects (six men, mean age 30 years, range $23-40$, and six women, mean age 28 years, range 20-39) using the reflectance spectrophotometry method described by Bjerring and Andersen. ${ }^{12}$ To evaluate the effect of light

Table Seven point scale for perception of argon laser stimuli

\begin{tabular}{|c|c|c|c|}
\hline Perception & Scale & $\begin{array}{l}\text { Abbrev- } \\
\text { iation }\end{array}$ & Rating \\
\hline \multirow{6}{*}{$\begin{array}{l}\text { Very intense pin prick and } \\
\text { burning after sensation } \\
\text { Intense pin prick } \\
\text { Sharp distinct pin prick } \\
\text { Distinct pin prick } \\
\text { Weak pin prick. warmth } \\
\text { Faint pin prick. slight } \\
\text { touch, faint warmth }\end{array}$} & 6 & VIPP BS & Yery strong pain \\
\hline & 5 & IPP & Strong pain \\
\hline & 4 & SDPP & Moderate pain \\
\hline & 3 & DPP & Threshold of pain \\
\hline & 2 & $\mathrm{PP} W$ & Pre-pain \\
\hline & 1 & $\mathrm{PP} / \mathrm{T} / \mathrm{W}$ & Threshold of \\
\hline No sensation & 0 & NS & \\
\hline
\end{tabular}

absorption, carbon black was used for covering the total area of stimulation.

The influence of laser type and stimulus parameters on thresholds The sensory and pain thresholds to $\mathrm{CO}_{2}$ and argon laser stimulation were determined in 12 subjects (six men, mean age 27 , range $17-38$, and six women, mean age 24 , range 16-30) for different stimulus durations $(50,100$, 200 , and $500 \mathrm{~ms}$ ) and different beam diameters (1, 2, 3 and 5 $\mathrm{mm}$ ). The thresholds were determined on normal skin and on skin blackened by carbon black.

Threshold differences between sexes To study differences in thresholds between sexes, a total of 52 young volunteers were tested ( 30 men, mean age 32 years, range 18-46;22 women, mean age 29 years, range 18 to 42 ). The argon laser beam ( $200 \mathrm{~ms}$ duration, $3 \mathrm{~mm}$ beam diameter) was applied to the dorsum of the hand.

Intra-individual variation in threshold In order to test variability in sensory and pain thresholds five successive determinations were performed in 12 subjects (seven men, mean age 26 years, range $20-31$, five women, mean age 27 years, range 18-31). The argon laser stimulus (200 ms duration, $3 \mathrm{~mm}$ beam diameter) was applied on the dorsum of the left hand.

\section{Results}

The influence of skin temperature on thresholds The skin temperature was found to influence the sensory and pain argon laser thresholds (fig 1). At skin temperatures of $28^{\circ} \mathrm{C}$ and $30^{\circ} \mathrm{C}$ the sensory threshold was characterised as a feeling of warmth. At skin temperatures of $32^{\circ} \mathrm{C}$ the threshold was slightly greater than at $30^{\circ} \mathrm{C}$ and the feeling was changed to a

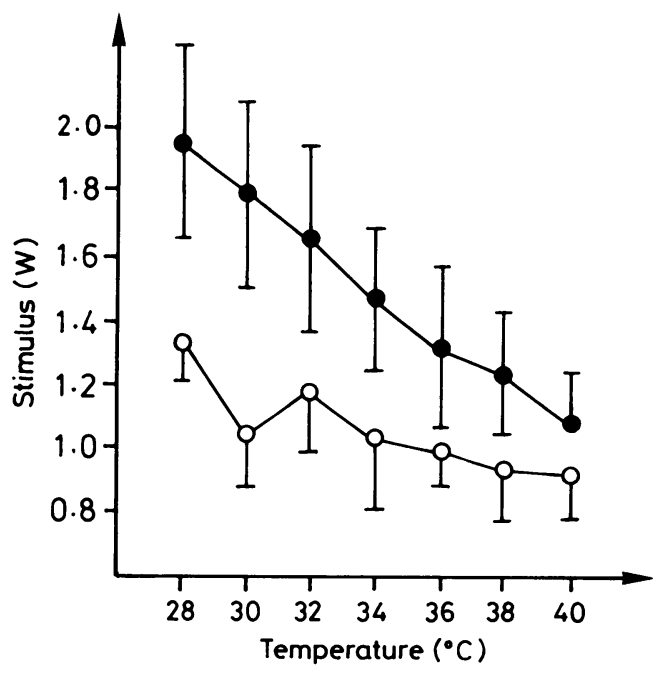

Fig 1 The mean sensory $(\bigcirc)$ and pain $(\bigcirc)$ threshold as a function of skin temperature. The vertical bars indicate the standard deviation of the mean. The laser pulses $1200 \mathrm{~ms}$ duration, $3 \mathrm{~mm}$ heam diameter) were applied to the dorsum of the hand. 12 subjects (18-34 years old). 
slight pin prick, and no perception of warmth could be identified. The laser intensity needed to activate this pin prick perception decreased with increasing skin temperature $\left(32-40^{\circ} \mathrm{C}\right)$. The mean argon laser pain threshold decreased for an increase in skin

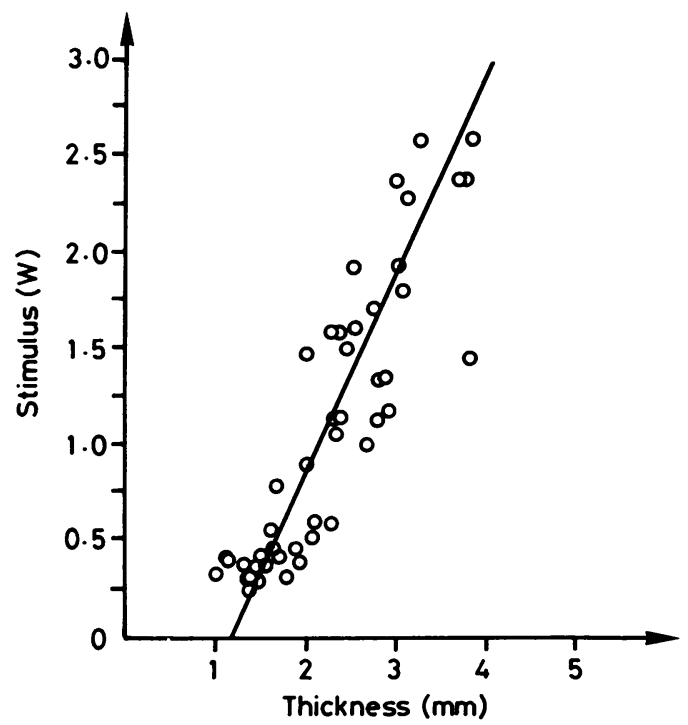

Fig 2 The influence of skin thickness on argon laser sensory threshold ( $200 \mathrm{~ms}$ duration, $3 \mathrm{~mm}$ beam diameter). A total of 55 points were selected on the lateral part of the $S 1$-dermatome. A regression line $(0.84 \mathrm{~mm}-0.86)$ was fitted through the points $(R=0 \cdot 89)$. One subject (male, 28 years old).

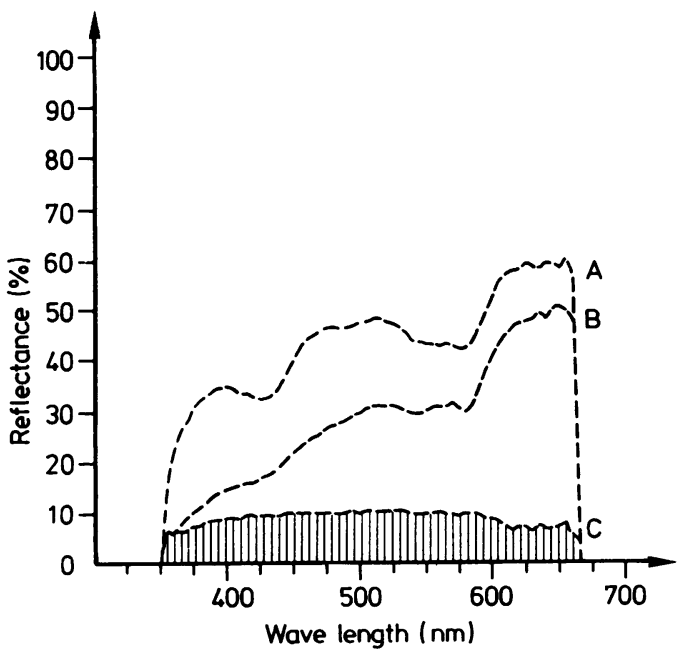

Fig 3 An example of skin reflectance determined from: $A$, caucasian pale skin, $B$, moderately pigmented skin, and $C$, skin covered with carbon black. One subject (male, 28 years old). temperature over the whole range of temperatures. The difference between sensory and pain thresholds was greater at low than at high temperatures.

The influence of skin thickness on thresholds A high degree of variability in thresholds was observed between dermatomes. This could be due to differences in receptor density or optical and physical skin characteristics. To study the effect of skin thickness on sensory argon laser threshold an experiment was performed on the lateral part of the leg where a total of 45 points was investigated. The sensory argon threshold increased linearly with the thickness (fig 2). One millimetre increase in skin thickness, required $0.84 \mathrm{~W}$ higher stimulus intensity to elicit the threshold sensation. This strong dependence of skin thickness requires the highest degree of attention when thresholds are compared.

Skin reflectance To evaluate the actual reflectance from normal and blackened skin at argon laser wavelengths $(0.488$ and $0.515 \mu \mathrm{m})$ a scanning reflectance spectrophotometer was used. The reflectance from caucasian pale skin was approximately $45 \%$ at the argon wavelengths, and $32 \%$ for moderately pigmented skin (fig 3). When the skin was blackened with carbon black, the reflectance dropped to around $12 \%$ in the entire visible spectrum. If a mean reflectance of $38 \%$ is assumed for non blackened skin the ratio between the absorbed energy for blackened and non blackened skin is 1.4 . It should therefore be expected that 1.4 times more energy was needed to reach threshold on non blackened skin compared with blackened, but ratios of 1.75 and 2.57 were found indicating that other factors than reflectance are involved.

The influence of stimulus parameters, laser type and skin colour on thresholds

The relation between laser beam diameter, duration and power of the stimulus The influence of stimulus parameters on the argon laser thresholds were initially determined for $1 \cdot 0,2 \cdot 0,3 \cdot 0$ and $5.0 \mathrm{~mm}$ beam diameters, and pulse durations of 50 to $500 \mathrm{~ms}$. For all diameters the thresholds decreased logarithmically for increasing stimulus duration (fig $4 \mathrm{~A}, \mathrm{~B}$ ). The sensory threshold was always lower than the corresponding pain threshold. The mean ratios between sensory and pain thresholds increased for increasing beam diameter and were $0.49,0.54,0.56$ and 0.65 for $1 \cdot 0,2 \cdot 0,3.0$ and $5.0 \mathrm{~mm}$ respectively. The difference between sensory and pain thresholds became smaller for increasing pulse duration. For 100 and $500 \mathrm{~ms}$ duration the mean differences were 0.87 and $0.40 \mathrm{~W}$ respectively.

The relation between laser beam diameter, duration and energy density of stimulus The energy density was expressed in $\mathrm{mJ} / \mathrm{mm}^{2}$ : 
$\mathrm{mJ} / \mathrm{mm}^{2}=$ Power(W) $\times$ Pulse duration (ms)/Beam diameter ${ }^{2}\left(\mathrm{~mm}^{2}\right)$.

Higher energy densities were required for increasing pulse durations (fig 4C, D). The threshold energy densities decreased for increasing beam diameters. The variability in threshold energy density was highest for the smallest beam diameter $(1.0 \mathrm{~mm})$.

When pain stimulation was performed with short pulse durations (50 and $100 \mathrm{~ms}$ ) and/or small beam diameters $(\leqslant 2 \mathrm{~mm})$ superficial burn lesions could be observed. To avoid damage of the skin a longer pulse duration $(200 \mathrm{~ms})$ and a larger beam diameter $(3 \mathrm{~mm})$ was chosen in the following investigations. The pulses were applied to normal hairy skin on the dorsum of the hand in the C7-dermatome. The skin temperature was kept constant at $33^{\circ} \mathrm{C}$ during the experiments.

The influence of laser type and skin colouring on thresholds The influence of laser type and skin colouring on thresholds was then determined for a fixed beam diameter of $3 \mathrm{~mm}$ and pulse durations varied from 50 to $500 \mathrm{~ms}$. The thresholds to $\mathrm{CO}_{2}$ laser stimulation on normal and blackened skin decreased
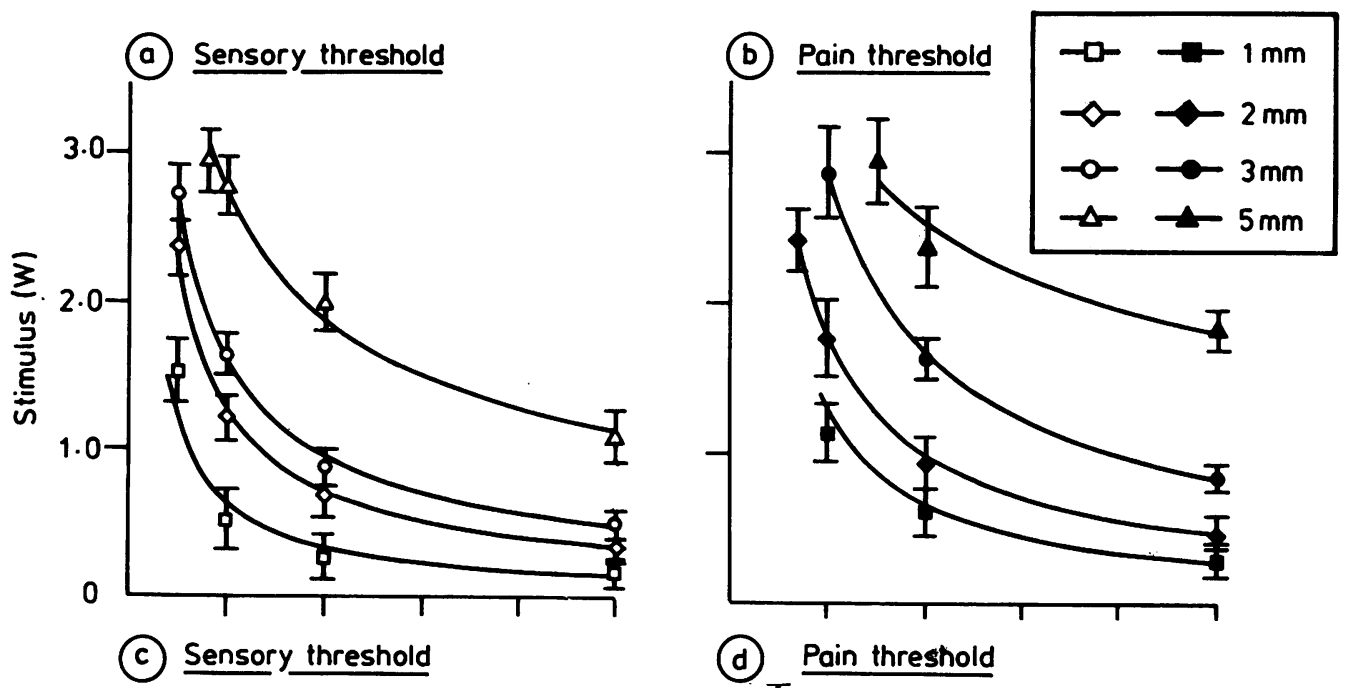

(d) Pain threshold

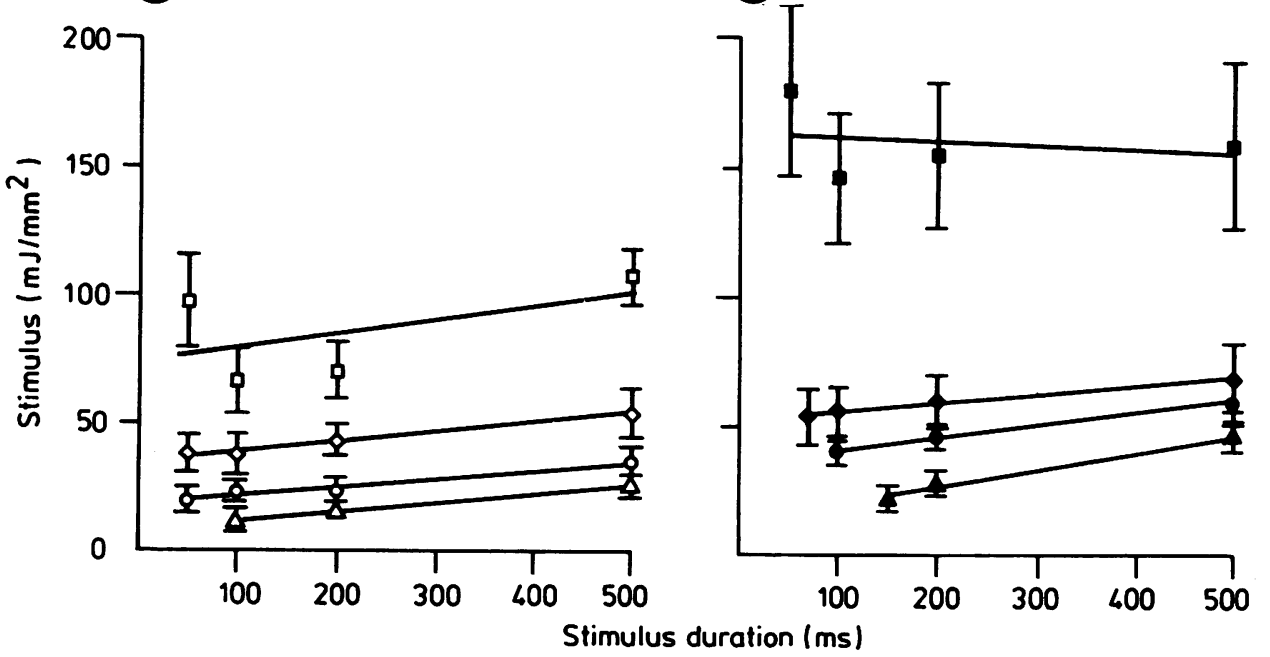

Fig 4 The mean thermal sensory $(A, C)$ and pain $(B, D)$ thresholds for different argon laser pulse durations and beam diameters expressed in power $(W)$ and energy density $\left(\mathrm{mJ} / \mathrm{mm}^{2}\right)$. The stimuli were applied to the dorsum of the hand in 12 subjects (16-38 years old). The vertical bars indicate the standard error of the mean. Logarithmic curves are fitted through the points in $A$ and $B$, whereas the points in $C$ and $D$ are fitted by linear regression lines. 
(a) $\mathrm{CO}_{2}$ Thresholds normal skin
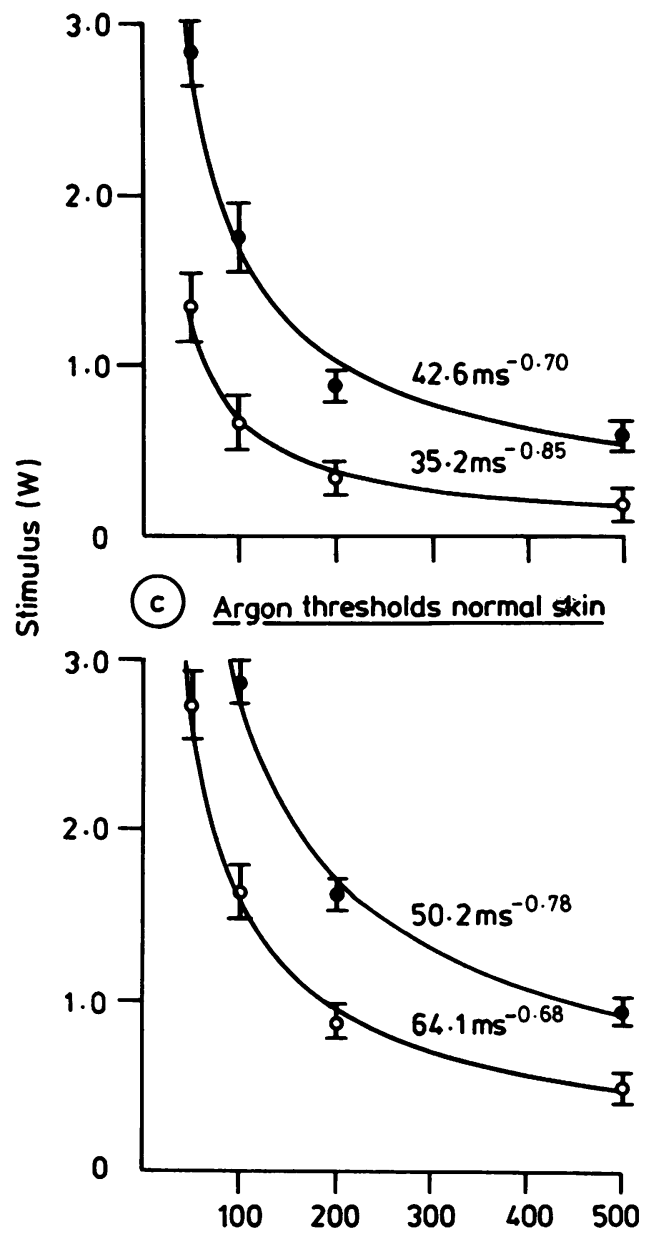

b) $\mathrm{CO}_{2}$ Thresholds blackened skin

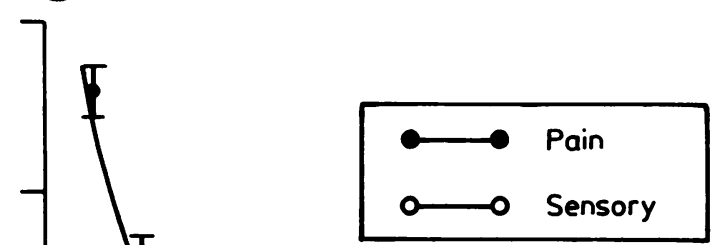

(d) Argon thresholds blackened skin

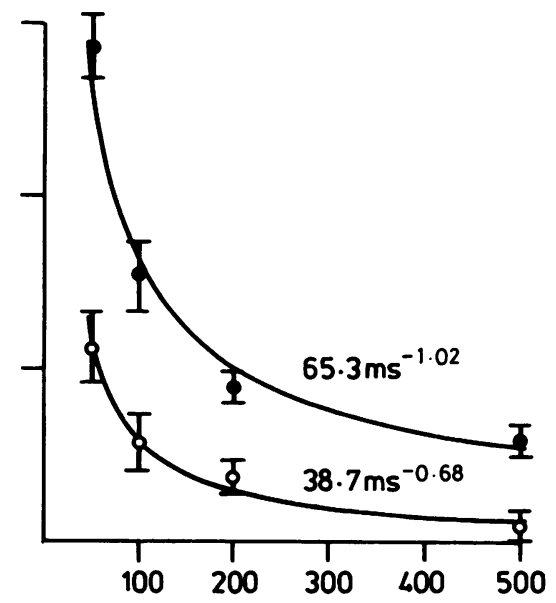

Stimulus duration (ms)

Fig 5 The mean thermal sensory $(\bigcirc)$ and pain $(O)$ thresholds for different laser pulse durations. The laser pulse $(3$ $\mathrm{mm}$ beam diameter) was applied to the dorsum of the hand in 12 subjects (16-38 years old). A: $\mathrm{CO}_{2}$ laser thresholds for normal skin. B: $\mathrm{CO}_{2}$ laser thresholds for blackened skin. C: Argon laser threshold for normal skin. D: Argon laser thresholds for blackened skin. The vertical bars indicate the standard error of the mean. Logarithmic curves are fitted through the points.

also logarithmically for increasing pulse duration. Covering the skin by carbon black did not change the thresholds to $\mathrm{CO}_{2}$ laser stimulation (fig 5A, B). The ratios between sensory and pain thresholds were found to be $0.39\left(C_{2}\right.$ laser, normal skin) and 0.39 ( $\mathrm{CO}_{2}$ laser, blackened skin).

Argon laser thresholds determined on blackened skin were significantly lower than on normal skin (fig 5C, D). Argon thresholds on blackened skin were similar to $\mathrm{CO}_{2}$ laser thresholds on normal and blackened skin.
In the following investigations a laser impulse of $200 \mathrm{~ms}$ duration and $3 \mathrm{~mm}$ diameter was applied on skin with known thickness, temperature and reflectance.

Difference in threshold between sexes The thresholds were determined in a larger group of volunteers $(30$ men, mean age 32 years and 22 women, mean age 29 years). The mean sensory threshold ( \pm SD) to argon laser stimulation was significantly $(\mathrm{p} \leqslant 0.01$, Student $t$ test) larger for men $(0.92 \pm 0.27 \mathrm{~W})$ than for women $(0.67 \pm 0.18 \mathrm{~W})$. The mean pain threshold $( \pm S D)$ to 
argon laser stimulation was also found to be significantly $(p \leqslant 0.025)$ larger for men $(1.7 \pm 0.38 \mathrm{~W})$ than for women $(1.23 \pm 0.39 \mathrm{~W})$.

Intra-individual variation in thresholds For each of the 12 volunteers five successive threshold determinations were performed within one hour. The standard deviations for the sensory thresholds ranged from $0.02 \mathrm{~W}$ to $0.17 \mathrm{~W}$, and from $0.02 \mathrm{~W}$ to $0.12 \mathrm{~W}$ for the pain threshold. The intra-individual standard deviation were found to $0.07 \mathrm{~W}$ (coefficient of variation $9.3 \%$ ) for the sensory threshold, and $0.06 \mathrm{~W}$ (coefficient of variation $4.3 \%$ ) for the pain threshold.

\section{Discussion}

Thermal thresholds - sensory and pain - have been determined in various stimulus conditions to elucidate the different factors affecting the thresholds.

\section{Influence of skin temperature on thresholds}

Sensory threshold For surface skin temperatures below $32^{\circ} \mathrm{C}$ the perception at sensory threshold was described as warmth. When skin temperature increased above $32^{\circ} \mathrm{C}$ the sensory threshold changed to slight pin prick. For skin temperatures above $32^{\circ} \mathrm{C}$ the threshold for warmth might not be perceived because there is a constant firing from the warmth receptors. ${ }^{14} \mathrm{~A}$ slightly higher energy of the laser impulse was then perceived as pin prick indicating that other receptors are stimulated.

Pain threshold We suggest that the decrease in pain threshold with increasing temperature is due to a smaller difference between the intracutaneous temperature and the noxious temperature. Intracutaneous temperatures at $42^{\circ} \mathrm{C}$ to $45^{\circ} \mathrm{C}$ are found to activate the polymodal nociceptors. ${ }^{15-19}$

When the skin temperature was increased it became more difficult to distinguish between pain and sensory thresholds, because both sensations were projected into the same tactile modality. Pain threshold to electrical stimulation was also found to decrease for increasing skin temperature ${ }^{20}$ which might suggest that the general excitability of the receptors could be changed by temperature.

The influence of skin properties on thresholds In a preliminary experiment a great variation in thresholds was observed when stimuli were applied to different dermatomes. This could be due to differences in receptor density and skin characteristics. The skin thickness was found to be a very important factor.

The influence of stimulus parameters, laser type and skin colour on thresholds

Stimulus parameters The logarithmic decrease in sensation and pain for increasing stimulus confirm previous findings in experiments with stimulation by a focused tungsten bulb, ${ }^{21-23}$ and with a $\mathrm{CO}_{2}$ laser stimulation. ${ }^{8}$ The results are similar to findings in experiments with electrical stimulation where the current needed to evoke the feeling of pressure decreased logarithmically with increasing stimulus duration. ${ }^{2420}$

The decrease in energy density for increasing beam diameter has previously been described by Biehl et al ${ }^{8}$ who used a $\mathrm{CO}_{2}$ laser. The decrease might be explained by (1) spatial summation from receptors and (2) a relatively greater heat transmission for the larger diameters due to the relative decrease in radial heat loss compared with smaller diameters.

Willer et $\mathrm{al}^{25}$ used an argon laser for threshold detection, but found no change in energy density for increased beam diameter $(0.25 \mathrm{~mm}$ to $1.00 \mathrm{~mm})$. Biehl et $\mathrm{al}^{8}$ found a constant threshold energy density for increasing $\mathrm{CO}_{2}$ laser pulse duration. Using an argon laser we found an increase in threshold energy density for increasing pulse duration. A major part of the argon laser light is absorbed by the haemoglobin in the upper dermis, and part of the absorbed energy is removed by vascular circulation in the papillary capillaries and in the superficial vascular plexus. For longer pulse durations a higher amount of energy can be removed by circulation before termination of the stimulus, and hence a higher amount of energy is required to reach the threshold.

Laser type and skin colouring The significant differences in thresholds for argon and $\mathrm{CO}_{2}$ lasers might be explained by differences in skin reflectance? for visible and infrared light. If the skin was blackened, the argon laser thresholds became identical to the $\mathrm{CO}_{2}$ laser thresholds, because the main part of the energy is absorbed superficially for both laser beams. The visible light is absorbed by the black colour and the infrared radiation by the water content of the superficial skin layers. ${ }^{6} \mathrm{CO}_{2}$ laser thresholds were not affected by blackening of the skin because skin reflectance is less than $2 \%$ for wave lengths greater than $4 \mu \mathrm{m}$ and independent of skin pigments. ${ }^{9}$ It has been argued that lasers in the visible range are not suitable as thermal stimulators, since up to $98 \%$ of the energy may be reflected from the skin surface, and blackening of the skin therefore is necessary. ${ }^{8}$ Using a scanning reflectance spectrophotometric method, the skin reflectance in the range between 488 and $515 \mathrm{~nm}$ was found to vary between $32 \%$ for moderately pigmented skin to $45 \%$ for pale caucasian skin. When carbon black was used for blackening of the skin, reflectance dropped to approximately $12 \%$.

For visible argon laser stimulation on normal skin the energy is readily transmitted to the upper dermis $^{11}{ }^{12}$ and partly absorbed by the melanin in the 
basal epidermal layers. The remaining part is mainly absorbed by the haemoglobin in the papillary capillaries and in the superficial vascular plexus, where part of the energy is carried away by the vascular circulation. Differences between argon thresholds on blackened and normal skin could only partly be explained by the differences in reflectance between blackened and normal skin. The vascular circulation and the infrared radiation from the heated carbon on the skin surface may explain this discrepancy.

For argon stimulation on blackened skin the energy is absorbed in the very superficial epidermal skin layers and subsequently transmitted to the receptor level by thermal conduction identical to the heat conduction existing for infrared stimulation. Biehl et $\mathrm{al}^{8}$ found the ratio between sensory and pain thresholds to be 0.7 for $\mathrm{CO}_{2}$ laser stimulation with a $5.6 \mathrm{~mm}$ beam diameter. We found that the ratio increased from 0.49 for $1 \mathrm{~mm}$ diameter to 0.63 for $5 \mathrm{~mm}$ beam diameters, suggesting that the beam diameter may influence the range between sensory and pain threshold.

Superficial burn lesions To avoid the very high skin temperatures and hence superficial burn lesions we have chosen to use an argon laser stimulus with a pulse duration of $200 \mathrm{~ms}$ and a large beam diameter $(\geqslant 2 \mathrm{~mm})$. In previous studies short (10-100 ms) $\mathrm{CO}_{2}$ laser pulses have been reported ${ }^{78}$ to cause burn lesions. The $\mathrm{CO}_{2}$ lasers do more easily generate burn lesions compared with the argon laser since all the energy is absorbed superficially, and very high superficial skin temperatures can arise.

Difference in threshold between sexes Sensory and pain thresholds to brief argon laser pulses were significantly lower for females than for males. This difference could be explained by the in general lower skin thickness for females than for males. The cutaneous pain threshold to electrical stimulation has been described to be significantly lower for women than for men. ${ }^{26}$

Intra-individual variability in thresholds The threshold measurements were highly constant between consecutive determinations (coefficient of variation $9.3 \%$ for sensory threshold, and $4.3 \%$ for pain threshold). Previously $\mathrm{CO}_{2}$ laser stimulations with larger beam diameters $(9 \mathrm{~mm})$, resulted in variations of more than $20 \%{ }^{8}$ This larger variation could be due to changes in skin temperature and/or skin properties.

Conclusion Visible argon laser light is found to be suitable for thermal stimulation. Compared with $\mathrm{CO}_{2}$ lasers argon lasers have two advantages: (1) the argon light can be transmitted by optical fibres, and (2) the very high superficial skin temperatures, and hence the superficial burn lesions can be avoided.

As a compromise the argon laser stimulus parame- ter was chosen to $200 \mathrm{~ms}$ duration and $3 \mathrm{~mm}$ beam diameter. Both stimuli and skin conditions could modulate the thermal thresholds which demands standard experimental conditions when thermal thresholds are used for quantitative comparisons. During controlled conditions the intra-individual variation was very low, and the method is therefore suggested as a quantitative clinical technique with application in the assessment of function in the thermal and nociceptive pathways and in the study of clinical and subclinical abnormalities of thermal and pain perception.

This work was supported by the Danish Cancer Society (87-006). The authors thank Professor A Rosenfalck, Aalborg University, for very helpful suggestions and critically reading the manuscript. We also thank Professor $\mathrm{H}$ Zachariae, Department of Dermatology, Marselisborg Hospital, for allowing us to use the laser.

\section{References}

1 Wall PD. Physiological mechanisms involved in the production and relief of pain. In: Bonica JJ, Procalli P, Pagni CA, eds. Recent Advances on Pain. Springfield: Charles C. Thomas, 1976:36-63.

2 Mor J, Carmon A. Laser emitted radiant heat for pain research. Pain 1975;1:233-7.

3 Mayer RA, Walker RE, Mountcastle VB. A laser stimulator for the study of cutaneous thermal and pain sensation. IEEE Trans Bio Eng 1976;1:54-60.

4 Carmon A, Mor J., Goldberg J. Evoked cerebral responses to noxious thermal stimuli in humans. Exp Brain Res 1976;25:103-7.

5 Bromm B, Jahnke MT, Treede R-D. Responses of human cutaneous afferens to $\mathrm{CO}_{2}$ laser stimuli causing pain. Exp Brain Res 1984;55:158-66.

6 Bargeron L:B, McCally RL, Farrell RA. Calculated and measured endothelial temperature histories of excised rabbit corneas exposed to infrared radiation. Exp Eye Res 1981;32:241-50.

7 Coger RW, Kenton B, Pinsky JJ, Crue BL, Carmon A, Friedman Y. Somatosensory evoked potentials and noxious stimulation in patients with intractable non-cancer pain syndromes. Psychiatry Res 1980;2:279-94.

8 Biehl R, Treede R-D, Bromm B. Pain ratings of short radiant heat pulses. In: Bromm B, ed. Pain Measurement in Man. Amsterdam: Elsevier, 1984:397-408.

9 Hardy JD. Body temperature regulation. In: Mountcastle VB, ed. Medical Physiology. St. Louis: Mosby, 1980:1417-56.

10 Parrish J, Anderson R. Considerations of selectivity in laser therapy. In: Noe JM, Rosen S, eds. Cutaneous Laser Therapy: Principles and Methods. New York: Wiley \& Sons, 1983:41-52.

11 Halldörsson T, Langerholc J. Thermodynamic analysis of laser irradiation of biological tissue. Applied Optics 1978;24:3948-58.

12 Cummins L, Nauenberg $M$. Thermal effects of laser radiation in biological tissue. Biophys J 1983:42:99-102.

13 Bjerring P, Andersen PH. Skin reflectance spectrophotometry. Photodermatology 1987;4:167-71.

14 Konietzny $F$, Hensel $H$. The neural basis of the sensory quality of warmth. In: Kenshalo DR, ed. Sensory Functions of the Skin of 
Humans. New York: Plenum Press, 1979:241-259.

15 Torebjork HE, Hallin RG. Skin receptors supplied by unmyelinated (C) fibres in man. In: Zotterman Y, ed. Sensory Functions of the Skin in Primates: with Special Reference to Man. Oxford: Pergamon Press, 1976:465-85.

16 LaMotte RH. Intensive and temporal determinants of thermal pain. In: Kenshalo DR, Ed. Sensory Functions of the Skin of Humans. New York: Plenum Press, 1979:327-61.

17 Gybels J, Handwerker HO, Van Hess J. A comparison between the discharges of human nociceptive nerve fibres and the subject's ratings of his sensation. $J$ Physiol (Lond.) 1979;292:193-206.

18 Van Hess J, Gybels J. C nociceptor activity in human nerve during painful and non painful skin stimulation. $J$ Neurol Neurosurg Psychiatry 1981;44:600-7.

19 Adriaensen H, Gybels J. Handwerker HO, Van Hess J. Response properties of thin myelinated (A- $\delta$ ) fibers in human skin nerves. J Neurophysiol 1983;49:111-22.

20 Notermans SLH. Measurement of pain threshold determined by electrical stimulation and its clinical application. Neurology 1966;16:1071-86.

21 Hardy JD, Wolff HG, Goodell H. Studies on pain: Discrimination of differences in intensity of a pain stimulus as a basis of a scale of pain intensity. J Clin Invest 1947;26:1152-8.

22 Hardy JD. Threshold of pain and reflex contraction as related to noxious stimulation. J Appl Physiol 1953;5:725-39.

23 Procacci P, Della Cortes M, Zoppi M, Romano S, Maresca M, Veogelin MR. Pain threshold measurement in man. In: Bonica JJ, Procacci P, Pagni CA, eds. Recent Advances on Pain. Springfield: Charles C. Thomas, 1976:105-47.

24 Buchthal F, Rosenfalck A. Evoked action potentials and conduction velocity in human sensory nerves. Brain Res 1966;3:1-122.

25 Willer JC, Boureau F, Berny J. Nociceptive flexion reflexes elicited by noxious laser radiant heat in man. Pain 1979;7:15-20.

26 Della Corte M, Procacci P, Bozza G, Buzzelli G. A study on the cutaneous pricking pain threshold in normal man. Arch Fisiol 1965;64:141-70. 